\title{
Enhancement of ice-phase precipitation caused by thermal forcing produces ghost echoes over the Tibetan Plateau
}

\author{
Yilun Chen $\mathbb{D}^{1,2}$, Aoqi Zhang $\mathbb{D}^{1,2}$, Shumin Chen ${ }^{1,2}$, Chaoyong $\mathrm{Tu}^{1,2}$, Weibiao $\mathrm{Li}^{1,2}$ and Yunfei Fu${ }^{3}$
}

Whether tall storms produce heavy precipitation is currently a controversial topic. Here, we used seven years of observations from the dual-frequency precipitation radar and found that there is a rare but unique vertical precipitation structure over the Tibetan Plateau. The radar echo peaks above the freezing height, which we refer to as a "ghost echo". The existence of a ghost echo increases the echo-top height but suppresses the increase in droplet size below it, and therefore weakens the near-surface precipitation. Compared with normal echoes, ghost echoes appear more often in the afternoon. The potentially unstable environment produced by thermal forcing is the main cause of ghost echoes, rather than the dynamic factor of wind shear. The ghost echo, which is essentially a mechanism of ice-phase precipitation enhancement, represents a type of tall but weak precipitation. Its existence adds to our current perception of the nature of precipitation.

npj Climate and Atmospheric Science (2021)4:41; https://doi.org/10.1038/s41612-021-00199-2

\section{INTRODUCTION}

The vertical structure of precipitation indicates the phase change and growth processes of precipitation particles and plays an important role in the global cycling of water and energy ${ }^{1}$. The echo-top height is one of the variables that can be used to characterize the vertical evolution of precipitation. Conventionally, tall precipitation is positively linked to heavy precipitation, especially over land ${ }^{2}$, which is also the basic principle of current satellite passive-remote-sensing precipitation algorithms ${ }^{3}$. However, some scientists have put forward an opposite view: that the heaviest precipitation mostly corresponds to less intense convection ${ }^{4}$. Also, the precipitation from passive-remote-sensing algorithms is obviously underestimated in coastal mountain regions during the East Asian monsoon, because the heavy precipitation in these parts mostly corresponds to low cloud tops, which is related to the process of warm rain ${ }^{3,5}$.

The echo slope is another key variable. The slope of Ku-band reflectivity is usually negative-that is, the reflectivity increases with decreasing height ${ }^{6}$. The reflectivity of extremely heavy precipitation increases substantially below the freezing height, indicating the importance of the collision-coalescence process (warm phase) $)^{7,8}$. In some rare cases, the radar echo will reach a peak in the ice-phase region, and then decrease as the altitude decreases, which is referred to here as a "ghost echo". This paper focuses on the formation mechanism of ghost echoes and their impact on precipitation.

In terms of ghost echo-like structures, some observations and mechanisms have been discussed in the literature. In the vicinity of the terrain, ground-based radar has observed a vertical structure with double maximum reflectivity: one is a bright band located at freezing height $(\sim 2 \mathrm{~km})$, and the other has the second-highest reflectivity at $\sim 4-4.5 \mathrm{~km}^{9-11}$. Early studies suggested that the temperature (approximately $-13^{\circ} \mathrm{C}$ to $-15^{\circ} \mathrm{C}$ ) at the second-highest reflectivity is conducive to the growth and aggregation of dendrites, but this upper-level reflectivity maximum is not critical to the mechanism for the enhancement of orographic precipitation ${ }^{11}$. Subsequent observations have shown that this structure mostly occurs when the central sector of the cyclone passes through the windward slope of a mountain. The strong shear triggered by the terrain forms a cellular overturning in the area between the two large values ${ }^{9,10}$. In a case study of the Olympic Mountains, the reflectivity maximum appearing above the freezing height was considered to have been caused by the high water vapor content encountering the uplift of the mountains, jointly affected by the low-level warm-rain process and the high-level ice-phase process $^{12,13}$. However, the mechanism of this structure and its influence on precipitation have not been well understood. For example, similar structures may also exist in flat areas, indicating that this is related to large-scale processes rather than orographic effects ${ }^{14}$. Studies have also suggested that this phenomenon may be due to the error of the instrumentmultiple scattering caused by tilted convection induces false echoes at the lower level ${ }^{15}$.

Although these studies mentioned above have discussed the enhancement of ice-phase precipitation, they were almost all based on case studies and offer no universal criteria. In addition, most of them were based on ground-based radars. Limited by the attenuation of the stronger precipitation in the lower level and the bright band at freezing height, the reliability of the reflectivity maximum in the ice-phase region is open to question. Spaceborne rain radars, on the other hand, can achieve top-down observations of precipitation structure over a large range and for a long time. The global precipitation measurement (GPM) core observatory's dual-frequency precipitation radar (DPR) has observed a secondary enhancement in reflectivity aloft in the Olympic Mountains, showing the potential for spaceborne radar to provide reliable estimates over mountainous areas ${ }^{13}$. Recently, we used tropical rainfall measuring mission (TRMM) precipitation radar (PR) observations to design a standard for quantitative identification of ghost echoes. It is found that ghost echoes occur more frequently in high latitudes than in low latitudes, and more

\footnotetext{
Guangdong Province Key Laboratory for Climate Change and Natural Disaster Studies, School of Atmospheric Sciences, Sun Yat-sen University, Zhuhai 519082, China. ${ }^{2}$ Southern Marine Science and Engineering Guangdong Laboratory (Zhuhai), Zhuhai 519082, China. ${ }^{3}$ School of Earth and Space Sciences, University of Science and Technology of China, Hefei 230026, China. ${ }^{凶}$ email: zhangaoq3@mail.sysu.edu.cn
} 
(a)

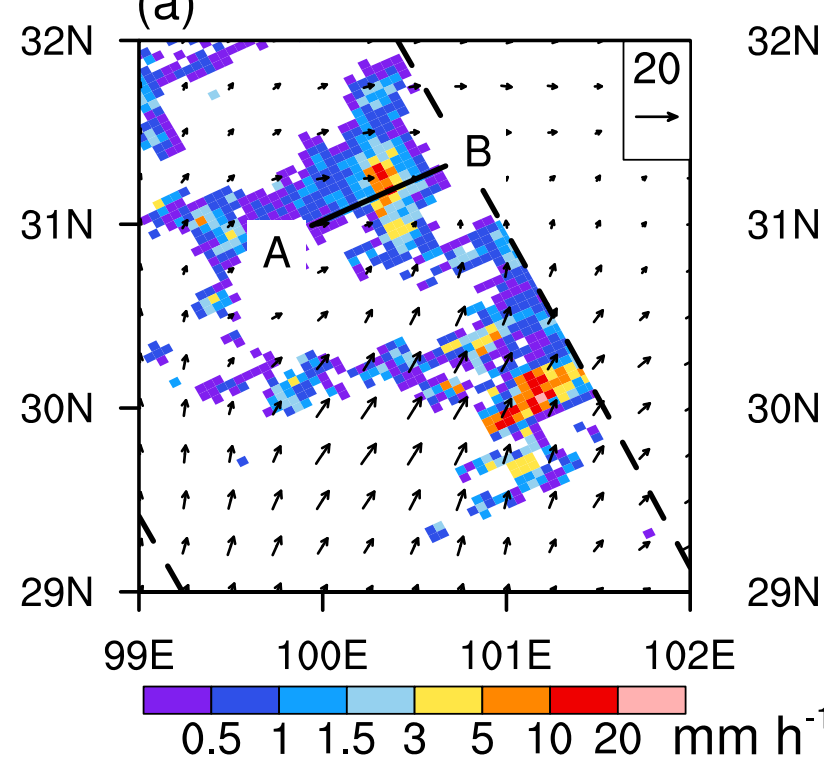

(b)

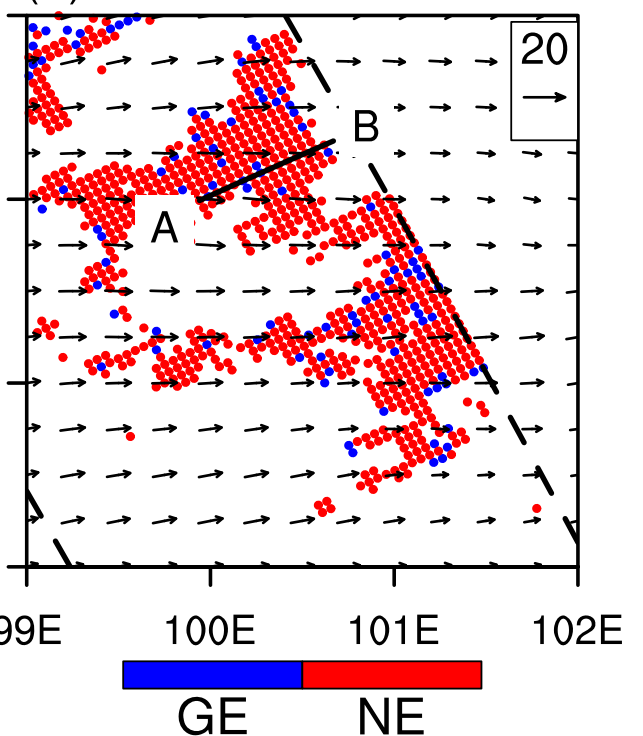

(c)

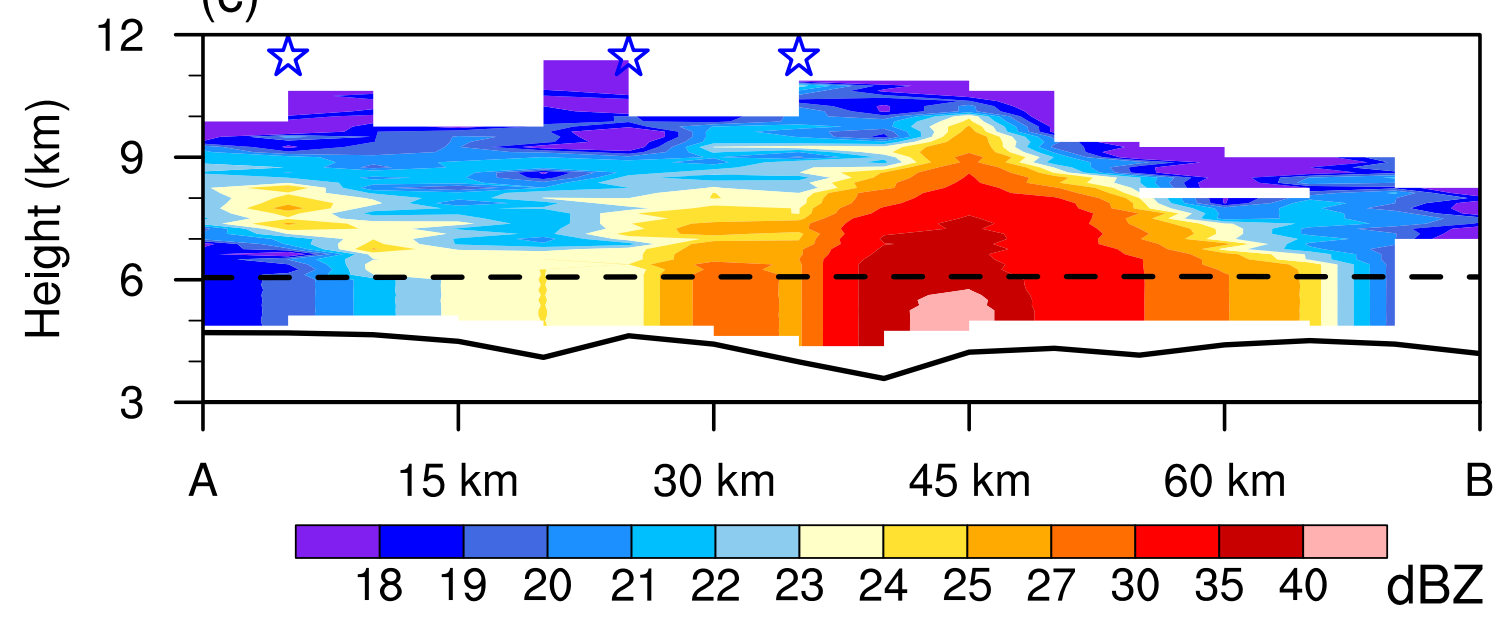

Fig. 1 Ghost echo case. a Near-surface rain rate and 550-hPa wind field. b Ghost-echo identification and 400-hPa wind field, in which blue denotes a ghost echo and red a normal echo. c Radar reflectivity of cross-section $A B$, in which pentagrams indicate the locations of ghostecho pixels. The dashed lines in (a) and (b) indicate the scanned swath of the radar. The dashed line in (c) indicates the freezing height. The solid line in (c) indicates the elevation.

frequently over land than over the ocean. The frequency of ghost echo is positively correlated with elevation (elevation between 0 and $2.5 \mathrm{~km}$ ). Over the Tibetan Plateau, Iranian Plateau, and Andes region, ghost echoes account for more than $2 \%$ of all precipitation pixels ${ }^{16}$. However, quantitative characteristics and generation mechanisms have not been given, especially over the Tibetan Plateau, a very high altitude area.

The Tibetan Plateau is the highest and largest plateau in the world, with the elevation of its main body being higher than $3 \mathrm{~km}$. Compared with surrounding areas, the thermal and dynamic conditions of the Tibetan Plateau are unique, which produces precipitation phenomena and mechanisms with regional characteristics ${ }^{17,18}$. Under the same surface sensible heat, the surface buoyancy flux of the Tibetan Plateau is $60 \%$ larger than that of eastern China at the same latitude because of the relatively low atmospheric density ${ }^{19}$. At the same time, the distance between the free convection top is closer to the surface, which makes it easier for shallow convection to be triggered over the Tibetan Plateau $^{20}$. When the capping inversion layer is broken, a unique popcorn-like cloud is generated over the plateau, which then develops into a deep and mature super convection system, moving eastward ${ }^{21}$.

Taking into account the Tibetan Plateau's high elevation and unique thermal and dynamic conditions, this paper focuses on the characteristics of ghost echoes over this region. Furthermore, the influence of ghost echoes on the structure of precipitation is investigated from a statistical perspective, and the generation mechanism of ghost echoes in this area is discussed.

\section{RESULTS}

\section{Ghost echo case}

Figure 1 shows a case of a ghost echo over the Tibetan Plateau that met our identification criteria. GPM DPR scanned across the area at $\sim 18: 00$ local time ( 11:00 UTC) on June 24, 2014, and captured two major precipitation areas, the centers of which are located in the north $\left(31.3^{\circ} \mathrm{N}, 100.3^{\circ} \mathrm{E}\right)$ and southeast $\left(30^{\circ} \mathrm{N}, 101^{\circ} \mathrm{E}\right)$ 
(a) GE

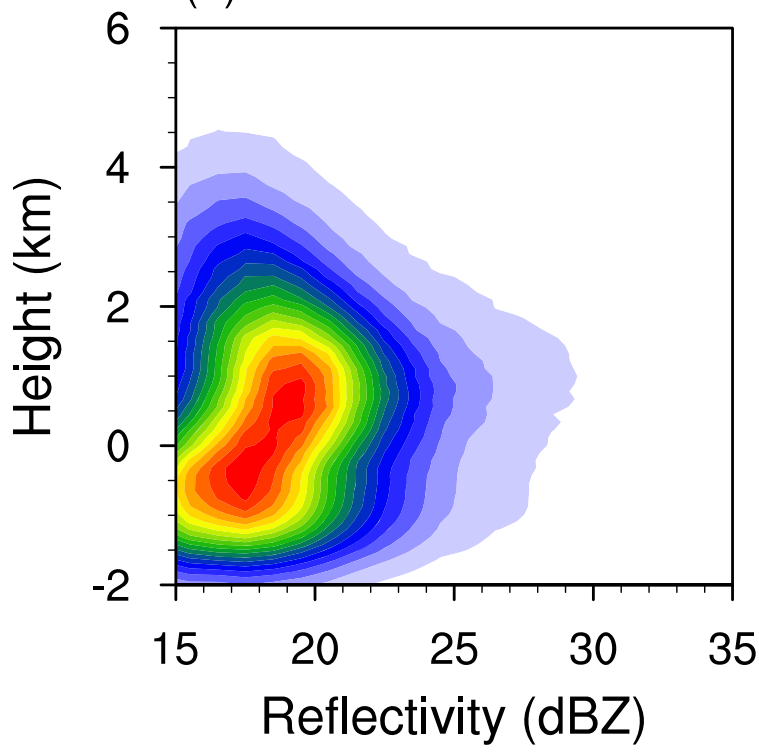

(b) NE

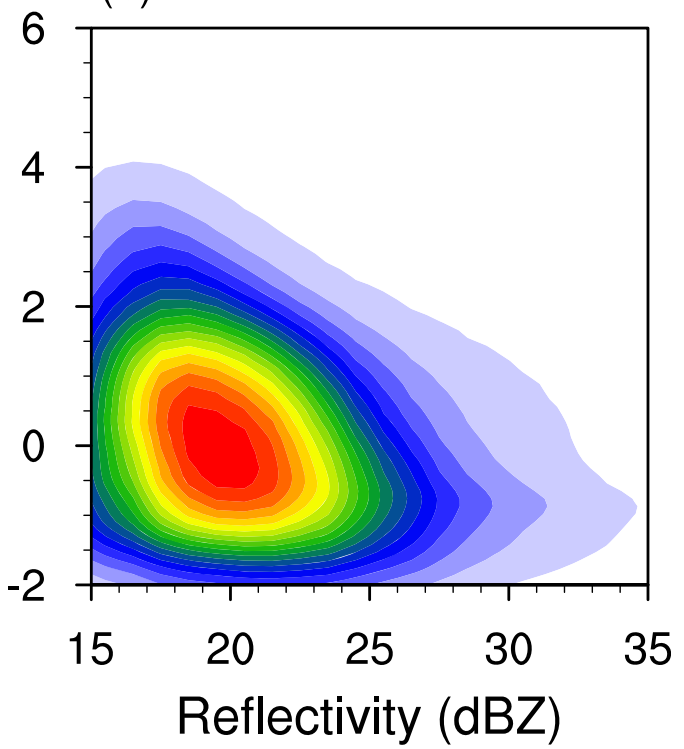

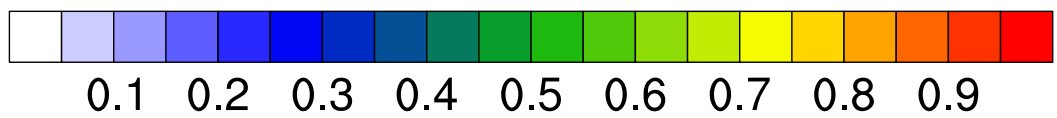

Fig. 2 Contoured frequency by altitude diagrams of reflectivity. a Ghost echo (GE). b Normal echo (NE). The coloring represents the joint

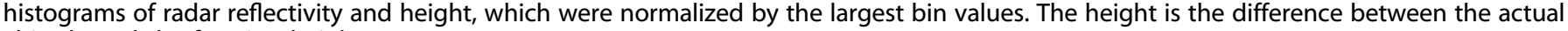
altitude and the freezing height.

of the figure. There was almost no ghost-echo structure in the heavy rain pixels, but a ghost echo did occur in the light rain pixels $\left(<1.5 \mathrm{~mm} \mathrm{~h}^{-1}\right)$ surrounding the precipitation center. On line $A B, a$ total of 3 pixels were identified to have ghost echoes, all of which were located on the west side of the heavy precipitation center. The height of the reflectivity maximum was $7-9 \mathrm{~km}$, which was significantly higher than the freezing height $(\sim 6 \mathrm{~km})$. Considering the near-surface and mid-level wind fields (a light breeze at $550 \mathrm{hPa}$ and a westerly wind of $\sim 10 \mathrm{~m} \mathrm{~s}^{-1}$ at $400 \mathrm{hPa}$ ), these three ghost-echo pixels were not produced by the tilted convective center at $45 \mathrm{~km}$ in Fig. 1c at the upper level. On the contrary, the reflectivity maxima of these ghost echoes were connected to the lower level through oblique downward paths, which may have affected the precipitation in their downstream region (east). Unlike the case of the Olympic Mountains, these ghost echoes did not exhibit a structure with double maximum reflectivity ${ }^{13}$, and there was no obvious bright band at the freezing level (the maximum reflectivity only existed in the ice-phase area). It is worth noting that the echo-top height of these ghost-echo pixels was similar to or even slightly higher than that of the pixels downstream, but the near-surface reflectivity was much smaller than the pixels downstream. For example, the reflectivity of the ghost echo near Point A (Fig. 1c) exceeded $25 \mathrm{dBZ}$, but the near-surface directly below it had a reflectivity of $\sim 19 \mathrm{dBZ}$. These precipitation-sized droplets may have been transported to a distance of $15 \mathrm{~km}$ with a reflectivity of $\sim 24 \mathrm{dBZ}$.

\section{Statistical differences between a ghost and normal echoes}

The vertical structure of a ghost echo shows robust differences from a normal echo, both in intensity and height (Fig. 2). The outlier contour (0.05) of the ghost echo reached up to $4.5 \mathrm{~km}$ above the freezing height, which was $\sim 0.5 \mathrm{~km}$ higher than that of the normal echo. The outlier contour of the ghost echo had an inflection point above the freezing height of $\sim 1.5 \mathrm{~km}$, and the echo slope changed from negative to positive; the slope of the normal echo also increased slightly at this height, but it was still negative, i.e., the shoulder observed previously ${ }^{14}$. For the modal contour (0.75), the difference between the two was even greater. The modal contour of the ghost echo decreased from $20 \mathrm{dBZ}$ at a height of $1.5 \mathrm{~km}$ to $16 \mathrm{dBZ}$ at a height of $-0.5 \mathrm{~km}$, with a slope of $2 \mathrm{~dB} \mathrm{~km}^{-1}$, and there was no increase in the echo below the freezing height. The modal contour of the normal echo showed an increasing trend with decreasing altitude, with a slope of $-2.5 \mathrm{~dB} \mathrm{~km}^{-1}$, which is consistent with most precipitation systems over land ${ }^{6}$. As for the vertical structure of the ghost echo itself, it usually presented a positively skewed distribution, with an average of $2.0 \mathrm{~km}$ above the freezing height, a thickness of $1.3 \mathrm{~km}$, and an intensity of $4.3 \mathrm{~dB}$ (Supplementary Fig. 1).

The echo-top height of the ghost-echo pixels was $\sim 0.8 \mathrm{~km}$ higher than that of the normal-echo pixels, but the average near-surface rain rate was $0.4 \mathrm{~mm} \mathrm{~h}^{-1}$ lower (Fig. 3a, b). This means that the existence of the ghost-echo structure raises the height of precipitation development but weakens the development of precipitation below it, indicating a unique mechanism for the enhancement of ice-phase precipitation. Previous explanations that deep precipitation is not necessarily heavy pay more attention to the importance of warm-rain processes (not deep) to heavy precipitation ${ }^{3,4}$, while ghost-echo structures raise the notion of ice-phase processes corresponding to weak precipitation. The droplet density $\left(\mathrm{dBN}_{\mathrm{w}}\right)$ of ghost and normal echoes was almost the same at the near-surface, but the effective droplet diameter $\left(D_{\mathrm{m}}\right)$ was smaller by $0.1 \mathrm{~mm}$ on average, indicating that ghost-echo structures decrease the near-surface rain rate by suppressing the growth of particle size below. This conclusion can also be obtained from the vertical profile of the droplet size distribution (Supplementary Fig. 2). $D_{\mathrm{m}}$ had a significant turning point at $1 \mathrm{~km}$ above the freezing height-that is, slightly lower than the height of maximum reflectivity in the ice region. 

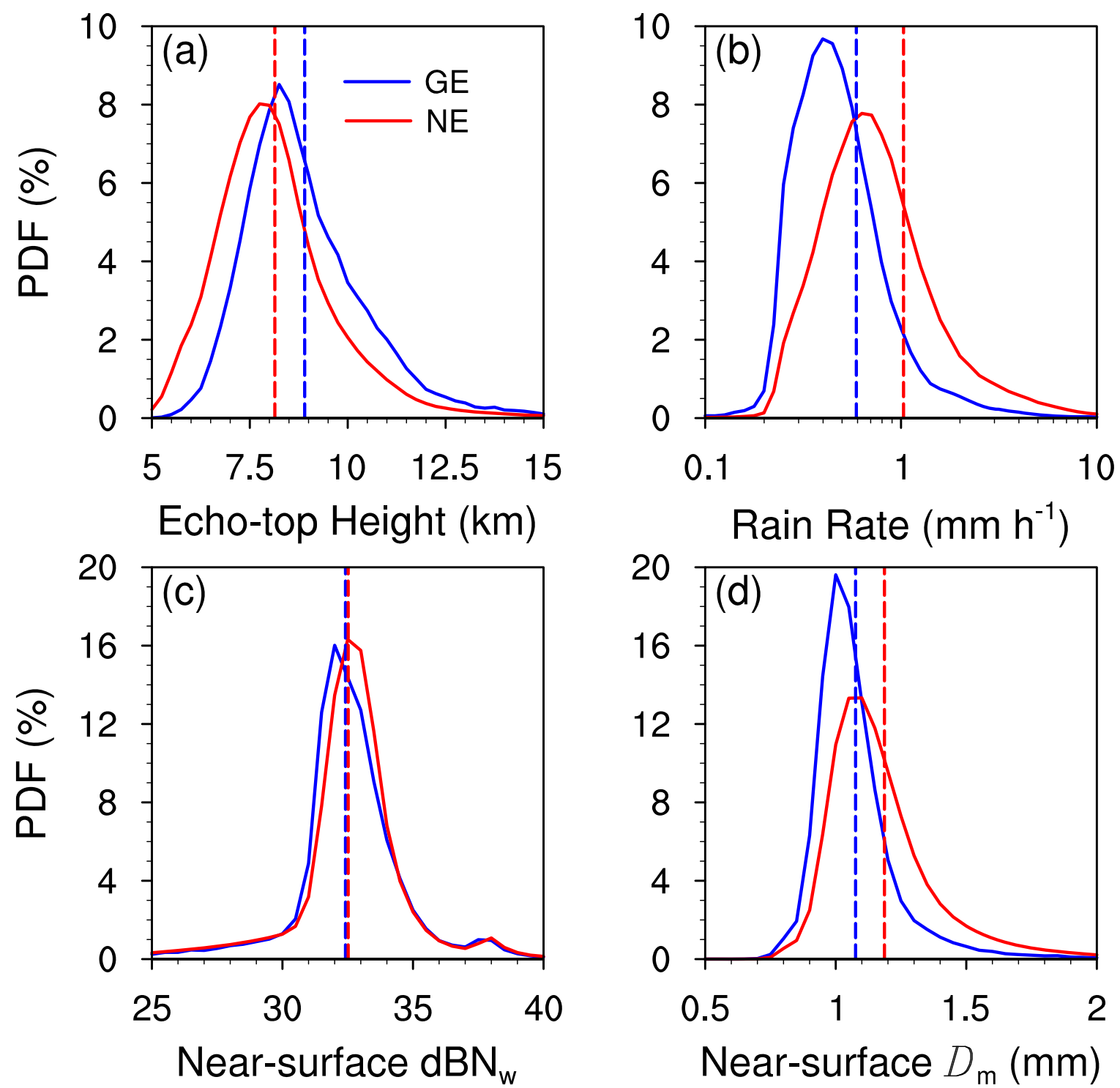

Fig. 3 Probability distribution function (PDF) of precipitation parameters for ghost echoes (GE) and normal echoes (NE). a Echo-top height. b Near-surface rain rate. c Near-surface droplet density $\left(\mathrm{dBN}_{\mathrm{w}}\right)$. d Near-surface effective droplet diameter $\left(D_{\mathrm{m}}\right)$. The dashed lines indicate the mean values.

\section{Ghost echo trigger mechanism}

Ghost and normal echoes showed distinct diurnal variation in terms of precipitation. Compared with the frequency of normal echoes, ghost echoes appeared more in the afternoon (most at 14:00 local time), similar at dusk, and less at night (Supplementary Fig. 3a). The difference in the echo-top height between the two was greater than $1 \mathrm{~km}$ at 16:00 local time, and less than $0.5 \mathrm{~km}$ at 08:00 local time (Supplementary Fig. 3b). The precipitation with normal echoes peaked at 16:00 and 19:00 local time, corresponding to the strongest afternoon heating and the most water vapor flux, respectively. The intensity of ghost-echo precipitation does not change much throughout the day (Supplementary Fig. 3c). The ghost-echo grid had a stronger updraft than that of the normal echo at the height $1 \mathrm{~km}$ above the freezing level, while the ascent velocity of the normal-echo grid was greater at the low level (Supplementary Fig. 4). These results indicate that the strong surface heating of the Tibetan Plateau may raise the height of the mixed layer in the afternoon ${ }^{21}$ and promote the upward propagation of the ascending movement (Supplementary Fig. 5). In a certain mode, it is conducive to the generation of a ghost echo, which then lifts the echo-top height but suppresses near-surface precipitation.

Using ERA5 hourly data at $550 \mathrm{hPa}$ and $400 \mathrm{hPa}$, we calculated the wind shear and equivalent potential temperature difference $\left(\frac{\partial \theta_{e}}{\partial z}\right)$ of the two types (Supplementary Fig. 6). The results showed that there was no obvious difference in wind shear. The median wind shear of ghost echoes was $7.73 \mathrm{~m} \mathrm{~s}^{-1}$, while that of normal echoes was $7.09 \mathrm{~m} \mathrm{~s}^{-1}$. Comparing the top $10 \%$ of the wind shear between the two, the difference was less than $1.5 \mathrm{~m} \mathrm{~s}^{-1}$ (Supplementary Fig. 6a). The median $\frac{\partial \theta_{e}}{\partial z}$ of ghost echoes was $-1.6 \mathrm{~K}$, indicating that the atmosphere is potentially unstable; the median $\frac{\partial \theta_{e}}{\partial z}$ of normal echoes was $0.8 \mathrm{~K}$, indicating an absolutely stable atmosphere (Supplementary Fig. 6b). Therefore, the formation of a ghost echo over the Tibetan Plateau can be attributed to thermodynamics, rather than strong wind shear (dynamics).

\section{DISCUSSION}

Precipitation over the Tibetan Plateau sometimes presents a unique ghost echo structure-that is, the radar reflectivity reaches 


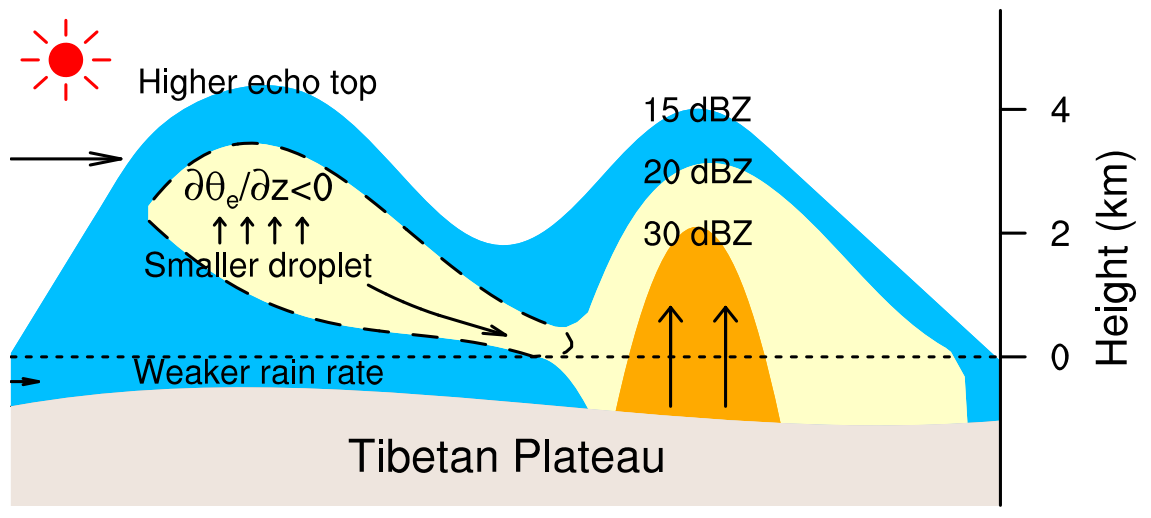

Fig. 4 Conceptual diagram of a ghost echo over the Tibetan Plateau. The ghost echo is on the left, and normal convection is on the right. The height is the difference between the actual altitude and the freezing height.

its peak in the ice-phase region above the freezing level (Fig. 4). This ghost-echo structure raises the echo-top height but reduces the near-surface rain rate. Past studies have usually focused on the low-echo centroid structure, which indicates the enhancement of precipitation via the low-level collision-coalescence process ${ }^{4}$. The ghost echo here is a structure that enhances ice-phase precipitation but suppresses low-level precipitation. It is also a counterexample to the existing theory because the ghost echo is relatively deep but has weak precipitation. Past studies have attributed the reflectivity increase in the ice phase observed by radar to microphysical growth ${ }^{11}$, strong wind shear ${ }^{9}$, large-scale effects $^{14}$, or instrument errors ${ }^{15}$. This study found that the reason for the appearance of ghost echoes over the Tibetan Plateau is more likely to be down to thermodynamics rather than wind shear. As a result of this structure and the accompanying mid-level ascent, many particles are lifted by updrafts $\sim 2 \mathrm{~km}$ above the freezing height and do not fall, reducing the particle size of lowlevel precipitation and weakening the local rain rate. Although wind shear may not be the cause of the ghost-echo structure, the particles accumulated in the ice-phase region may promote precipitation in adjacent areas due to wind shear.

The main finding of this paper is the unique ghost-echo structure over the Tibetan Plateau. This structure arises from the equally unique thermodynamic conditions of the Tibetan Plateau, and its influence on precipitation is different from other mechanisms of precipitation growth. Separating the concept of ghost-echo structure from the traditional theory of strong convection and heavy rainfall in the afternoon will help improve our understanding of the physical process of precipitation.

The Tibetan Plateau is the most sensitive area in response to climate change. As the altitude rises, the warming trend also tends to increase $\mathrm{e}^{22}$. On the one hand, surface air warming and moistening contribute to the generation of unstable environment and trigger deep convective clouds ${ }^{23}$, which provides a favorable environment for ghost echoes. On the other hand, warming and wind stilling lowers the Bowen ratio and cause a decrease in surface sensible heat ${ }^{23}$, which may suppress the generation of ghost echoes. In the context of current global warming, how will the frequency of ghost echoes change? It deserves our further attention.

\section{METHODS}

\section{Data}

We used the DPR_NS (Ku normal scan) data from GPM 2ADPR V08 in the Northern Hemisphere summer (June-August) from 2014 to 2020. These data provide the vertical profile of radar reflectivity and droplet size distribution at the pixel level and give the height of the freezing level in each pixel. The horizontal resolution of the data is $5 \mathrm{~km}$ and the vertical interval is $125 \mathrm{~m}$. As a spaceborne active instrument, GPM DPR provides rain-sensing both day and night. Compared with the TRMM PR launched in 1997, GPM DPR observes from two frequencies and can effectively retrieve droplet size distribution. In addition, the variable pulse repetition frequency technique increases the sensitivity of precipitation detection from $0.4 \mathrm{~mm} \mathrm{~h}^{-1}$ of TRMM PR to $0.2 \mathrm{~mm} \mathrm{~h}^{-1}$ of GPM DPR. GPM helps recognize the temporal and spatial variations of global precipitation, microphysical structure, and latent heat, and how these characteristics affect the global cycling of the water cycle and energy ${ }^{24}$. Compared with limited local sites, the microphysical structure retrieved by GPM DPR is consistent with ground-based observation $\mathrm{s}^{25}$.

ERA5 is the fifth generation ECMWF atmospheric reanalysis. It was used to provide hourly meteorological fields on pressure levels with a horizontal resolution of $31 \mathrm{~km}$.

\section{Identification of ghost echoes}

Our recent study involved designing a set of ghost-echo identification criteria based on TRMM PR observations ${ }^{16}$. GPM DPR and TRMM PR differ in their instrument sensitivity and vertical intervals, so we improved the algorithm as follows:

1. The echo-top height is higher than the freezing level, and precipitation exists at the near-surface to ensure that this precipitation pixel contains the ice-phase process;

2. There are three consecutive layers with reflectivity at least $0.5 \mathrm{~dB}$ greater than the next lower layer (slope of $4 \mathrm{~dB} \mathrm{~km}^{-1}$ ) in the icephase region, and the reflectivity of each layer is greater than $14.5 \mathrm{dBZ}$. Meanwhile, maximum reflectivity should be in the icephase region.

Those that met the above two requirements at the same time were defined as ghost echoes, and those that did not meet requirement 2 but did meet requirement 1 were defined as normal echoes. Over the Tibetan Plateau (altitude higher than $3 \mathrm{~km}$ ), a total of $\sim 70,000$ ghost-echo pixels were identified (Supplementary Fig. 7). These pixel-level data were used to calculate the basic characteristics of ghost echoes.

\section{Matching of ghost-echo pixels with ERA5 grids}

GPM DPR and ERA5 have different resolutions. An ERA5 grid usually contains more than 10 DPR pixels. It is inappropriate to use ERA5 grids directly to represent each DPR pixel. Here, if the ERA5 grid contained more than six ice precipitation pixels (ghost-echo pixel plus normal-echo pixel), it was defined as an ice-phase precipitation grid, which avoided the influence of a wide range of clear skies on the statistics. If there were at least three ghost-echo pixels in the ice-phase precipitation grid, this grid was defined as a ghost-echo grid; otherwise, it was a normal-echo grid. After calculation, there were $\sim 5700$ ghost-echo grids and $\sim 29,000$ normalecho grids, the sample size of which was sufficient for further statistical analysis. These grid data were used to calculate the thermodynamic and dynamic characteristics of ghost and normal echoes. 


\section{DATA AVAILABILITY}

GPM DPR data are taken from https://gpm.nasa.gov/data/directory. ERA5 data are archived at https://cds.climate.copernicus.eu/cdsapp\#!/dataset/reanalysis-era5pressure-levels?tab $=$ overview.

\section{CODE AVAILABILITY}

The code developed to analyze the data of the current study is available on request from the corresponding author.

Received: 11 May 2021; Accepted: 17 July 2021; Published online: 02 August 2021

\section{REFERENCES}

1. Tao, W. K. et al. Retrieval of latent heating from TRMM measurements. B Am. Meteorol. Soc. 87, 1555-1572 (2006).

2. Wang, T. C. \& Tang, G. Q. Spatial variability and linkage between extreme convections and extreme precipitation revealed by 22 -year space-borne precipitation radar data. Geophys. Res. Lett. 47, e2020GL088437 (2020).

3. Shige, S. \& Kummerow, C. D. Precipitation-top heights of heavy orographic rainfall in the Asian monsoon region. J. Atmos. Sci. 73, 3009-3024 (2016).

4. Hamada, A., Takayabu, Y. N., Liu, C. \& Zipser, E. J. Weak linkage between the heaviest rainfall and tallest storms. Nat. Commun. 6, 6213 (2015).

5. Sohn, B. J., Ryu, G. H., Song, H. J. \& Ou, M. L. Characteristic features of warm-type rain-producing heavy rainfall over the Korean peninsula inferred from TRMM measurements. Mon. Weather Rev. 141, 3873-3888 (2013).

6. Ni, X., Liu, C. T. \& Zipser, E. Ice microphysical properties near the tops of deep convective cores implied by the GPM dual-frequency radar observations. J. Atmos. Sci. 76, 2899-2917 (2019).

7. Porcacchia, L., Kirstetter, P. E., Maggioni, V. \& Tanelli, S. Investigating the GPM dual-frequency precipitation radar signatures of low-level precipitation enhancement. Q. J. R. Meteor. Soc. 145, 3161-3174 (2019).

8. Hamada, A. \& Takayabu, Y. N. Large-scale environmental conditions related to midsummer extreme rainfall events around Japan in the TRMM region. J. Clim. 31, 6933-6945 (2018).

9. Medina, S., Sukovich, E. \& Houze, R. A. Vertical structures of precipitation in cyclones crossing the Oregon cascades. Mon. Weather Rev. 135, 3565-3586 (2007).

10. Medina, S., Smull, B. F., Houze, R. A. \& Steiner, M. Cross-barrier flow during orographic precipitation events: results from MAP and IMPROVE. J. Atmos. Sci. 62, 3580-3598 (2005).

11. Houze, R. A. \& Medina, S. Turbulence as a mechanism for orographic precipitation enhancement. J. Atmos. Sci. 62, 3599-3623 (2005).

12. Zagrodnik, J. P., McMurdie, L. \& Conrick, R. Microphysical enhancement processes within stratiform precipitation on the barrier and sub-barrier scale of the Olympic mountains. Mon. Weather Rev. 149, 503-520 (2021).

13. McMurdie, L. A. et al. Terrain-enhanced precipitation processes above the melting layer: results from OLYMPEX. J. Geophys. Res. Atmos. 123, 12194-12209 (2018).

14. Kingsmill, D. E., Neiman, P. J., Ralph, F. M. \& White, A. B. Synoptic and topographic variability of northern California precipitation characteristics in landfalling winter storms observed during CALJET. Mon. Weather Rev. 134, 2072-2094 (2006).

15. Battaglia, A., Mroz, K., Tanelli, S., Tridon, F. \& Kirstetter, P. E. Multiple-scatteringinduced "ghost echoes" in GPM DPR observations of a tornadic supercell. J. Appl. Meteorol. Clim. 55, 1653-1666 (2016).

16. Zhang, A. Q., Li, W. B., Chen, S. M., Chen, Y. L. \& Fu, Y. F. Satellite observations of reflectivity maxima above the freezing level induced by terrain. Adv. Atmos. Sci. 38, 627-640 (2021).

17. Fu, Y. F. et al. Land-surface processes and summer-cloud-precipitation characteristics in the Tibetan Plateau and their effects on downstream weather: a review and perspective. Natl Sci. Rev. 7, 500-515 (2020).

18. Liu, X. L., Liu, Y. M., Wang, X. C. \& Wu, G. X. Large-scale dynamics and moisture sources of the precipitation over the western Tibetan plateau in boreal winter. J. Geophys. Res. Atmos. 125, e2019JD032133 (2020).
19. Wang, Y. et al. Why are there more summer afternoon low clouds over the Tibetan plateau compared to eastern China? Geophys. Res. Lett. 47, e2020GL089665 (2020).

20. Li, Y. Y. \& Zhang, M. H. Cumulus over the Tibetan plateau in the summer based on CloudSat-CALIPSO data. J. Clim. 29, 1219-1230 (2016).

21. Xu, X. D. et al. A comprehensive physical pattern of land-air dynamic and thermal structure on the Qinghai-Xizang Plateau. Sci. China Ser. D. 45, 577-594 (2002).

22. Liu, X. D. \& Chen, B. D. Climatic warming in the Tibetan Plateau during recent decades. Int J. Climatol. 20, 1729-1742 (2000).

23. Yang, K. et al. Recent climate changes over the Tibetan Plateau and their impacts on energy and water cycle: a review. Glob. Planet Change 112, 79-91 (2014).

24. Skofronick-Jackson, G. et al. The global precipitation measurement (GPM) mission's scientific achievements and societal contributions: reviewing four years of advanced rain and snow observations. Q. J. R. Meteor. Soc. 144, 27-48 (2018).

25. Ryu, J., Song, H. J., Sohn, B. J. \& Liu, C. Global distribution of three types of drop size distribution representing heavy rainfall from GPM/DPR measurements. Geophys. Res. Lett. 48, e2020GL090871 (2021).

\section{ACKNOWLEDGEMENTS}

This work was supported by the Guangdong Major Project of Basic and Applied Basic Research (Grant No. 2020B0301030004), National Natural Science Foundation of China (Grant Nos. 91837310, 42005062, and 42075004), the Fundamental Research Funds for the Central Universities Sun Yat-sen University (Grant number 2021qntd29), the Innovation Group Project of Southern Marine Science and Engineering Guangdong Laboratory (Zhuhai) (Grant number 311021009), and the Fundamental Research Funds for the Guangzhou Science and Technology Plan Project (Grant number 20193010036).

\section{AUTHOR CONTRIBUTIONS}

Y.C. and A.Z. conceived the idea and propose this study. All the authors discussed the concepts. Y.C. conducted the data analyses. The manuscript was drafted by Y.C. and edited by all authors.

\section{COMPETING INTERESTS}

The authors declare no competing interests.

\section{ADDITIONAL INFORMATION}

Supplementary information The online version contains supplementary material available at https://doi.org/10.1038/s41612-021-00199-2.

Correspondence and requests for materials should be addressed to A.Z.

Reprints and permission information is available at http://www.nature.com/ reprints

Publisher's note Springer Nature remains neutral with regard to jurisdictional claims in published maps and institutional affiliations.

(i) Open Access This article is licensed under a Creative Commons adaptation, distribution and reproduction in any medium or format, as long as you give appropriate credit to the original author(s) and the source, provide a link to the Creative Commons license, and indicate if changes were made. The images or other third party material in this article are included in the article's Creative Commons license, unless indicated otherwise in a credit line to the material. If material is not included in the article's Creative Commons license and your intended use is not permitted by statutory regulation or exceeds the permitted use, you will need to obtain permission directly from the copyright holder. To view a copy of this license, visit http://creativecommons. org/licenses/by/4.0/.

(c) The Author(s) 2021 